\title{
Erratum to: Compartmental tongue resection with submental island flap reconstruction for large carcinoma of the oral tongue
}

\author{
Sameh Roshdy ${ }^{1}$ - Mohamed Elbadrawy ${ }^{1}$ • Ashraf Khater ${ }^{1}$ • Islam A. Elzahaby ${ }^{1}$.

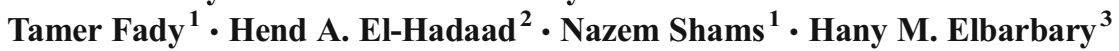

Published online: 8 June 2017

(C) Springer-Verlag Berlin Heidelberg 2017

\section{Erratum to: Oral and Maxillofacial Surgery}

DOI 10.1007/s10006-017-0627-0

One of the sharing author surgeon, Islam A. Elzahaby, was missing in the original version of this article. He needs to be included as fourth author.

The original article was corrected.

The online version of the original article can be found at http://dx.doi.org/ 10.1007/s10006-017-0627-0

Ashraf Khater

dr.ashrafkhater@yahoo.com

Sameh Roshdy

samehroshdy20@gmail.com

Mohamed Elbadrawy

mohammed_elbadrawy2003@yahoo.com

Islam A. Elzahaby

islamabdouu2010@yahoo.com

Tamer Fady

tamerfady@hotmail.com

Hend A. El-Hadaad

hend_am@yahoo.com
Nazem Shams

shamsnazem@hotmail.com

Hany M. Elbarbary

hany.abdeltwab@med.asu.edu.eg

1 Department of Surgical Oncology, Mansoura Oncology Center (OCMU), Faculty of Medicine, Mansoura University, Mansoura, Egypt

2 Clinical Oncology \& Nuclear Medicine, Faculty of Medicine, Mansoura University, Mansoura, Egypt

3 Department of General Surgery, Faculty of Medicine, Ein-Shams University, Cairo, Egypt 